IJADR

International Journal of Alcohol and Drug Research

The Official Journal of the Kettil Bruun Society for Social and Epidemiological Research on Alcohol

doi: 10.7895/ijadr.v4i1.190

IJADR, 2015, 4(1), 85 - 89

ISSN: 1925-7066

\title{
Addiction, recovery and moral agency: Philosophical considerations
}

\author{
Susanne Uusitalo \\ Department of Behavioural Sciences and Philosophy/Philosophy, University of Turku, Finland
}

\begin{abstract}
Aims: The purpose of this paper is to argue that it is important to recognize that addicts are morally accountable even for their addictive action, as moral agency is more generally an important factor in full-blown human agency. The challenge is to identify the problems that addicts have in their agency without discarding their potentially full-blown agency.
\end{abstract}

Design: In philosophy of agency, moral responsibility and accountability, in particular, may refer to control over one’s action. I discuss this control as reason-responsiveness and, on a more general level, illustrate the importance of moral agency to human agency with a contrasting example of psychopaths and addicts as agents.

Measures: A philosophical analysis is carried out in order to argue for the relevance and importance of moral accountability in therapeutic models of addiction.

Findings: The example of psychopaths and addicts illustrates that moral agency is part of full-blown human agency, as psychopaths are generally believed to lack moral skills common to non-psychopathic individuals. I argue that addicts are not analogous to psychopaths in the framework of moral agency in this respect.

Conclusions: By fleshing out the conceptual considerations in the framework of addiction therapies, I clarify the relevance and importance of moral accountability in therapeutic models of addiction. If evidence-based therapies attempt to restore the addict's full-fledged agency at least in respect to addiction, then acknowledging addicts' moral accountability for their action does matter.

Philosophical interest in addiction is manifold. One area of interest lies in questions of agency. Philosophers of agency concentrate on issues relating to the moral and legal responsibility of addicts (e.g., Poland \& Graham, 2011; Wallace, 1999; Watson, 1999). This may seem to differ from approaches within the sciences, which focus either on the etiological factors that cause addiction or the mechanisms involved in addiction that may cast more light on the prospects of therapeutic models, prevention measures, and public policies. The purpose of this paper is to argue that it is important to recognize that addicts are morally accountable even for their addictive actions. As moral agency is an important factor in full-blown human agency more generally, the consequences of recognizing addicts' moral agency may be useful in recovery. The point is not to argue that addictive action is always morally relevant behavior, but that addicts are moral agents in the sense that, other things being equal, they are reasonresponsive to moral reasons, and if the addictive action involves a moral dimension-say, a morally wrong-making feature - the addict is morally accountable for that action. Analysis of moral agency and accountability, in particular, bears relevance to various therapeutic models developed on the basis of, and in line with, scientific research such as neuroscience.

The paper begins with a rough characterization of addiction that draws on the different notions provided by academics in different fields and the self-reported experiences of addicts. I suggest that, despite the apparent differences in these views, they do agree on some aspects of addiction. There is, furthermore, an underlying aspect that affects these views - namely, the notion of moral agency. As moral responsibility is, in this article, considered to be dependent on the control the agent has over his action, I will have a closer look at a notion of moral agency in order to account for the forward-looking moral agency in the therapeutic framework. I suggest that moral accountability partly constitutes moral agency, without which full-blown human agency cannot be actualized, and addicts must be considered as apt candidates for full-blown human agency. The idea of moral agency being a necessary feature of fullblown human agency is argued for with a disanalogy between addicts and psychopaths. 


\section{Characterization of Addiction}

Providing an account of addiction is a task worthy of a paper on its own, but here it will suffice to provide a characterization which captures features of addiction that are, first, paradigmatic of addiction and, second, relevant in the discussion of addicts' moral agency. The characterization follows, to some extent, a phenomenal account provided by R. Jay Wallace (1999).

The image of an addict in the grip of strong desires is a common enough view of addicts, even among themselves:

"Cravings are quite out of control. There's no logic to them, there's no sort of sense to them. I think it's quite a childish attitude. You've got this craving and come hell or high water this craving's gonna be fulfilled... It becomes quite sort of, out of perspective.” (Neale, Nettleton, \& Pickering, 2012, p. 55, emphases added)

Here, a recovering heroin user depicts her experience and captures the salient features of addictive desire, namely the strength of the desire, its resilience and the attention it receives in one's mind and reasoning. Addictive desires are a prominent feature of addiction. They persist and seem to be detached from one's evaluative judgments. It seems that no matter what happens, the desire has to be satisfied. The addict considers it childish to want the drug so much, regardless of anything, and yet the desire is not affected by this judgment. The other point that this addict depicts is the intensity of the desire. Her choice of words is telling. The reference to lack of control may refer to the strength of the desire as opposed to one's rational evaluation of the situation or one's will, or it can merely indicate that the craving is beyond one's rational agency.

These kinds of phenomenal features of addiction are supported by recent neuroscientific research. The desires play a role in two features of addiction-attentional bias and subjective craving. Of course, attentional bias is common to human agency in general, but according to Field and Cox (2008), attentional bias in drug addicts develops partly as a consequence of classical conditioning. When addicts encounter cues that evoke their drug-related stimuli, conditioning brings about an expectation to use the substance to which they are addicted. This expectation feeds the experience of subjective craving, and it thereby reinforces "the attention-grabbing properties of substancerelated cues" that the addicts encounter (ibid., p. 16). The addicts are thus sensitive to detecting drug-related cues and the focus of their attention is skewed.

\section{Addiction and Agency}

These features-strong desires and attentional bias-seem to affect addicts' agency. If the automatic and controlled processes in addiction are found to (mal)function in a way that impairs the agent's control over his action, the moral accountability of the agent for those actions is called into question. ${ }^{1}$ From a philosophical perspective, the view that addictive action is compulsive, in the sense that addicts simply lose control over their action, is not very appealing. Characterizing addicts' action by making analogies to external or internal physical overpowering forces does not present an accurate picture of addiction. Deeming the action unfree or compulsive in this way would be viewing it as something akin to a reflex. The idea of a brute desire forcing the addict to move hardly makes sense, as addictive action usually involves planning and complex intentional actions, even if it is probably the case that addictive behavior, such as pushing the button of a slot machine or smoking a cigarette, is usually automated and habitual (Wallace, 1999).

Addicts have reported that they deliberately undergo withdrawal in order to lower their tolerance (Ainslie, 2000). This highlights an essential aspect of an individual's agency, namely, reason-responsiveness. Deliberately undergoing withdrawal in order to lower tolerance is hardly based on a goal of simply satisfying the desire. The idea of compelling addictive desire seems to conflate two notions of desire: desire as liking and desire as wanting. ${ }^{2}$ Addicts seem to be able to engage in deliberation concerning their addictive behavior, and to carry out the results of their deliberation. They receive reasons and react to them (for more on reason-responsiveness, see Fischer \& Ravizza, 1998, and for more on addicts' reason-responsiveness, Uusitalo, Salmela, \& Nikkinen, 2013). Philosophers have tried to develop accounts in which addicts' agency is more or less maintained (e.g., Levy, 2006). My premise is that, other things being equal, addicts are agents just like nonaddicted people are in this respect (see for instance Foddy \& Savulescu, 2006; Levy, 2006). Agency is expressed in control over action, and this control consists of reasonresponsiveness.

Nevertheless, to consider addicts on a par with non-addicts seems to leave something out. The challenge is, then, to identify the problems that addicts have in their agency without discarding their agency (see for instance Pickard, 2012). This seems analogous with psychological research which, with the aim of improving addicts' mental wellbeing, tries to identify factors that contribute to their undesirable behavior concerning the object of their addiction (e.g., Heyman, 2009). Of course, such research is not always motivated by a goal of maintaining or empowering agency (see Jones, 2012), but by an aspiration to reduce the stigma and blame that addicts may encounter (for the attitudes of the therapeutic professionals see Pennonen \& Koski-Jännes, 2010; for reducing blame in clinical settings, see Pickard, 2013). In therapeutic models (e.g., Thompson, 2012), the pragmatic ends necessitate

\footnotetext{
1 For more on the philosophical discussion regarding whether addicts should be exempted from moral responsibility for their actions on the basis of an uncontrollable state or feature in addiction, or excused from the possible moral wrong they may have committed due to, say, duress, see Wallace (1998 \& 1999), Watson (1999), Poland and Graham (2011).

${ }^{2}$ See Watson (2004) for the distinction in philosophy and cf. Robinson and Berridge (2008) for the same kind of distinction in neuroscience.
} 
what seems like quite a thick notion of agency; it involves more than mere physical control of one's movements, and addicts need to be able to employ that kind of agency in their behavior to reach successful treatment outcomes. The question of addiction is not solely about whether addicts have the abilities to make choices, but is also a question of (moral) responsibility. This calls for a more detailed look at moral agency.

\section{Moral Agency}

Being reason-responsive- that is, receiving and reacting to reasons - contributes to the moral accountability of an agent's actions (Fischer \& Ravizza, 1998). This is, roughly, the control condition of moral responsibility. Consider, for instance, a sleepwalker who is walking over delicate prize flowers in a garden. He does not even receive reasons and is thus not morally responsible for destroying the flowers. In order to be morally responsible for one's action, one needs to be at least weakly responsive to reason. Insofar as the control condition is met, the agent is an apt candidate for reactive attitudes (ibid., p. 7). Even if addicts are more sensitive to the cues triggering their addictive craving, this, as such, does not automatically excuse them or make them exempt from moral responsibility, nor does it undermine their capacity for moral agency (in the sense in which they would be excused).

However, moral agency refers not only to being responsible for one's actions but also to being able to make and act on moral judgments, ceteris paribus, about one's actions. Agents are thus apt subjects for normative claims of moral nature. Moral agency requires agents to satisfy the control condition (for notions of responsibility, see Vincent, 2011) and to have the capacity to act on moral reasons. In this view, if addicts satisfy the criteria for moral agency, they deserve blame for their actions if they do something wrong, and they are apt candidates for ought-claims.

So why does it matter for therapeutic models whether the subject of therapy is assumed to be capable of moral agency? Moral agency, I argue, is a prerequisite for fullblown human agency. This can be illustrated by having a glance at the discussion about psychopaths and their agency; in general, they are agents that seem to be in control of their actions, just like addicts, in the sense that nothing seems to prevent them from acting the way in which they consider best. It has been suggested that, in their myopic actions, they suffer from the same kind of irrationalities that addicts have (Greenspan, 2003). However, not planning too far ahead may also be seen as a coping strategy: "One day at a time" is a motto used by recovering addicts (see, e.g., Neale, Nettleton, \& Pickering, 2012). It is a normative choice regarding what counts as a reason worthy of being followed. This suggests that a short time span in planning does not necessarily diminish one's agency. If it is accepted that shortsightedness per se does not diminish the agent's moral agency, psychopaths seem to have control over their actions by at least weakly reacting to reasons. Furthermore, psychopathy is characterized by impulsivity, and this could perhaps be considered akin to addicts' unruly desires.
In philosophical literature, psychopaths and addicts are usually considered to be paradigm cases of lacking moral responsibility (see, e.g., Fischer \& Ravizza, 1998; Wallace, 1998). Of course, the accuracy of that judgment depends on the nature of these two conditions, and the nature of both is contested. In particular, the answer to the question of what psychopathy is is far from clear. Instead of providing full-fledged accounts of the two, I highlight the characteristic of psychopathy that is not typical of addiction, but that is relevant to moral agency. There seems to be some agreement that psychopaths lack the capacity to feel and act according to moral emotions such as empathy (Blair, 2003; Greenspan, 2003; Levy, 2007). This is the point in which addicts and psychopaths differ in their agency. According to Greenspan (2003), and Glenn, Koleva, Iyer, Graham, \& Ditto (2010), psychopaths lack moral motivation. They fail to be motivated by moral reasons; that is, they are not responsive to them qua moral reasons. The lack is not similar to weak-willed agents when they fail to be motivated by better judgments; psychopaths seem to be deprived of moral practical thinking. Addicts are not typically amoral in this sense. They may well act for moral reasons, even if they may also commit morally wrong acts in order to maintain their habit. In contrast to psychopaths, however, their own reactions to these acts can be accompanied with negative effects such as guilt or shame: their abilities to be motivated by moral judgments exist (see Neale, Nettleton, \& Pickering, 2012). Thus, addicts are moral agents, whereas psychopaths lack moral agency.

If we accept that psychopaths lack the motivational effect of moral judgments and fail to appreciate moral reasons in a proper way (Cima, Tonnaer, \& Hauser, 2010; Greenspan, 2003), one could then argue that addicts also fail to appreciate moral reasons in a proper way, if or when they cause harm to themselves and others. Their failure is, however, different from that of psychopaths. Psychopaths are incapable of moral motivation, while addicts are not. Psychopaths' failure to exercise moral agency leaves their full-blown agency wanting. This is an important point because, by recognizing this, therapeutic models can make use of this motivational aspect of addicts. Models that treat addicts as eligibly full-blown agents may empower their agency and strengthen their self-governance.

\section{A Moral Dimension of Addicts' Recovery}

To be morally accountable, an agent must appropriately control his or her actions and be, therefore, an apt candidate for moral judgments. This assumes that an action that is attributed to the agent in an appropriate way is governed by normative standards of conduct, which also bring about expectations in others who share them (Eshleman, 2009). This kind of reasoning seems to be involved in addiction science when research is evaluated in terms of whether it has produced information that would place addicts' actions outside the scope of normative standards of conduct, and thus undermine the warrant of holding addicts morally accountable for their addictive actions. For instance, Alan I. Leshner (1997) motivates his promotion of the disease view of addiction by referring to the undesirable implications of blaming addicts. The satisfaction of the 
control condition makes the addicts blameworthy, and this means that the addicts are apt candidates for reactive attitudes such as resentment.

In a therapeutic framework, blaming addicts for their addictive actions may be counterproductive, as it may increase their guilt and shame and thus hinder their attempts to get rid of addiction. However, there is a difference between regarding someone as blameworthy and actually blaming them for an action (see also Pickard, 2013). Even if addicts are and are held morally responsible for their actions, there are various ways in which the latter may be expressed. In cases like this, aspired consequences play a role too in determining for instance the amount of blame and the ways in which it is expressed. In any case, the criterion of moral accountability rests on a vital aspect of agency, and fulfilling that criterion provides the agent with moral agency as well, at least in this respect.

Since therapeutic models are primarily designed to improve the well-being of addicts, or at least change their behavior regarding the object of their addictions, they may prefer a moral responsibility model that is consequentialist, in the sense that blaming (and praising) is expressed in order to achieve some further goal. This kind of agenda is compatible with what I have presented. In a review of the current evidence-based therapies for drug addicts in Norway, it was argued that the greatest treatment effect was reached when the addicts felt they and their choices, of which they felt they were in control, were respected (Johansen \& Bramness, 2012). As individuals eligible for full-blown human agency, they were held responsible for those choices. Some of the evidence-based models seem to rely on addicts' ability to make decisions concerning their treatment (see Johansen \& Bramness, 2012), and this, as an indication of shared normative standards of conduct, is another important feature contributing to desirable treatment effects.

\section{Concluding Remarks}

The U.S. National Institute of Drug Abuse demands that addicts be treated as whole human beings (NIDA, 2008), but what they seem to forget in this rhetoric is that fullblown human agency requires a moral dimension. My interest in moral accountability taps into this; one of the reasons why addicts may be empowered is to keep or restore their belief in their moral agency. This motivates their attempts at recovery. This, obviously, does not imply that prudential reasons are any less salient than moral ones in full-blown human agency. I suggest that while addicts' agency is sensitive to different kinds of challenges, by integrating moral discussion into agential discussion, it is possible to acknowledge normative standards of conduct in the characterization of their actions and further employ that in attempts at recovery. As the disanalogy between addicts and psychopaths suggests, lack of moral motivation seems to leave the agent deficient in his or her self-governance, but addicts' agency is not deficient in this way.

\section{References}

Ainslie, G. (2000). A research-based theory of addictive motivation. Law and Philosophy, 19(1), 77-115.

Blair, R. J. (2003). Neurobiological basis of psychopathy. British Journal of Psychiatry, 182, 5-7.

Cima, M., Tonnaer, F., \& Hauser, M. D. (2010). Psychopaths know right from wrong but don't care. Social Cognitive and Affective Neuroscience, 5, 5967.

Eshleman, A. (2009). Moral responsibility. In E. N. Zalta (Ed.), The Stanford encyclopedia of philosophy (Winter Edition). Retrieved from http://plato.stanford. edu/archives/win2009/entries/moral-responsibility/

Field, M., \& Cox, W. M. (2008). Attentional bias in addictive behaviors: A review of its development, causes, and consequences. Drug and Alcohol Dependence, 97, 1-20.

Fischer, J., \& Ravizza, M. (1998). Responsibility and control: A theory of moral responsibility. New York, NY, United States: Cambridge University Press.

Foddy, B., \& Savulescu, J. (2006). Addiction and autonomy: Can addicted people consent to the prescription of their drug of addiction? Bioethics, 20, $1-15$.

Glenn, A. I., Koleva, S., Iyer, R., Graham, J., \& Ditto, P. H. (2010). Moral identity in psychopathy. Judgement and Decision Making, 5(7), 497-505.

Greenspan, P. S. (2003). Responsible psychopaths. Philosophical Psychology, 16(3), 417-429.

Heyman, G. (2009). Addiction: A disorder of choice. Cambridge, MA, United States: Harvard University Press.

Johansen, A. B, \& Bramness, J. (2012). Psykososial og medikamentell behandling ved rusavhengighet [Psychosocial and pharmacological treatment for drug addiction]. In S. Biong \& S. Ytrehus (Eds.), Helsehjelp til personer med rusproblemer [Health care for people with addictions] (pp. 121-142). Oslo: Cappelen Damm Akademisk.

Jones, D. (2012). Creatively confronting addiction. The Lancet, 379(Jan 7), 20.

Leshner, A. I. (1997). Addiction is a brain disease, and it matters. Science, new series, 278(5335), 45-47.

Levy, N. (2006). Autonomy and addiction. Canadian Journal of Philosophy, 36(3), 427-448.

Levy, N. (2007). Neuroethics: Challenges for the 21st century. Cambridge, United Kingdom: Cambridge University Press.

National Institute on Drug Abuse. (2008). Addiction science: From molecules to managed care. Retrieved on Sept. 24, 2012, from http://www.drugabuse.gov/ publications/addiction-science

Neale, J., Nettleton, S., \& Pickering, L. (2012). The everyday lives of recovering heroin users. London, England: RSA.

Pennonen, M., \& Koski-Jännes, A. (2010). Päihdealanammattilaisten käsityksiä aineriippuvuuksista [Conceptions of substance abuse by the professionals in addiction health care]. Juvenes, 18(3), 208-224.

Pickard, H. (2012). The purpose in chronic addiction. AJOB Neuroscience, 3(2), 40-49. 
Pickard, H. (2013). Responsibility without blame: Philosophical reflections on clinical practice. In K. W. M. Fulford, M. Davies, R. Gipps, J. Sadler, G. Stanghellini, \& T. Thornton (Eds.), The Oxford handbook of philosophy and psychiatry (pp.11341154). Oxford, United Kingdom: Oxford University Press.

Poland, J., \& Graham, G. (Eds.), (2011). Addiction and responsibility. Cambridge, MA, United States \& London, United Kingdom: The MIT Press.

Robinson, T. E., \& Berridge, K. C. (2008). Review. The incentive sensitization theory of addiction: Some current issues. Philosophical Transactions of the Royal Society B: Biological Sciences, 363, 31373146.

Thompson, G. (2012). A meaning-centered therapy for addictions. International Journal of Mental Health and Addiction, 10, 428-440.

Uusitalo, S., Salmela, M., \& Nikkinen, J. (2013). Addiction, agency and affects: Philosophical perspectives. Nordic Studies on Alcohol and Drugs, 30, 31-50.

Vincent, N. A. (2011.) A structured taxonomy of responsibility concepts. In N. Vincent, I. van de Poel, \& J. van den Hoven (Eds.), Moral responsibility: Beyond free will and determinism (pp. 15-35). Dordrecht, Netherlands: Springer Netherlands.

Wallace, R. J. (1999). Addiction as defect of the will: Some philosophical reflections. Law and Philosophy, 18(6), 621-654.

Wallace, R. J. (1998). Responsibility and moral sentiments. Cambridge, MA, United States \& London, UK: Harvard University Press.

Watson, G. (1999). Excusing addiction. Law and Philosophy, 18(6), 589-619.

Watson, G. (2004). Free agency. In G. Watson (Ed.), Agency and answerability: Selected essays. (pp. 1332). Oxford, UK: Oxford University Press 